\title{
Minimally Invasive Surgery for the Treatment of Ureteric Stones - State-of-the-Art Review
}

\author{
Radhika Bhanot (D) \\ Patrick Jones ${ }^{2,3}$ \\ Bhaskar Somani (iD) 1,3,4 \\ 'Department of Urology, University \\ Hospital Southampton NHS Trust, \\ Southampton, UK; ${ }^{2}$ Department of \\ Urology, Haukeland University Hospital, \\ Bergen, Norway; ${ }^{3}$ EAU Young Academic \\ Urology Urolithiasis and Endourology \\ Working Party, Arnhem, the Netherlands; \\ ${ }^{4}$ Manipal Academy of Higher Education, \\ Manipal, India
}

\begin{abstract}
The landscape of managing ureteric stones has evolved over the last few decades and several treatment options exist depending on the stone size, location, and other patient and stone factors. While open surgery is now rarely performed, the use of medical expulsive therapy (MET) has been controversial and perhaps only recommended for large distal ureteric stones. The mainstay treatment balances between shockwave lithotripsy (SWL) and ureteroscopy (URS), with the latter usually recommended for larger stones. While the principles of ureteric stone management have remained largely unchanged, the modern era has generated new methods and means to deliver it. Advancements have occurred in all domains of endourology to try and refine treatment and balance it with cost, patient choice and quality of life. Dissemination of technologies and demonstration of their efficacy and safety will eventually result in new recommendations among international guidelines and evolution of new gold standards.
\end{abstract}

Keywords: ureteroscopy, RIRS, percutaneous nephrolithotomy, kidney calculi, PCNL, SWL, ureteric stone

\section{Introduction}

The landscape of treatment for ureteric stone disease has evolved dramatically over the last 50 years. Historically, stone treatment was limited to interventions such as open surgery, but the evolution of minimally invasive surgery and the birth of endourology has led this to change. The story of endourology has had many chapters so far. Key milestones in this timeline include the first report of intra-ureteral lithotripsy in 1979 and the introduction of the flexible ureteroscope by Bagley et al in 1983. ${ }^{1,2}$ Research and development of new technologies has been a driving force for this change. Urolithiasis has a lifetime global prevalence of $14 \%$ and population-based studies reveal that this is rising. ${ }^{3,4}$ The underlying causes for this global change are considered multifactorial and relate to both host and environmental factors such as obesity, diabetes, smoking, climate change among many others. ${ }^{5-7}$ The burgeoning incidence of stone-related events has led to greater volume in stone surgery worldwide. Meta-analysis by Geraghty et al revealed the number of URS treatments has risen by over $250 \%$ over the past twenty years. ${ }^{8}$

From the urologist's perspective, there are a plethora of treatment modalities and modifications, which can be employed in order to deliver a "state-of-the-art" treatment to patients. These choices depend on a number of variables such as stone size, location and composition as well as surgeon experience and personal preference. Staying up to date with the inexorable rise in new endourology research can be challenging for the busy clinician and this scoping review serves to provide such an update. Advancements in
Correspondence: Bhaskar Somani Department of Urology, University Hospital Southampton NHS Trust, Southampton, UK

Email bhaskarsomani@yahoo.com 
SWL, URS as well as laparoscopic techniques for the treatment of ureteric stone disease are addressed.

\section{Shockwave Lithotripsy (SWL)}

Using 'shock waves' or acoustic pulses to fragment stones, which are located using either fluoroscopic or ultrasonic imaging, was introduced by Dornier, a German aircraft cooperation in 1980 during the investigation of pitting on supersonic aircraft. Since its first clinical application by Chaussy et al, the Human Model-1 (HM-1) lithotripter has undergone multiple revisions. Systems can now employ electrohydraulic, piezoelectric and electromagnetic generators. ${ }^{9}$ The advent of mobile, multifunctional lithotripters has expanded the treatment possibilities for ureteric stones. This has rendered SWL more accessible to smaller centres and more available in the acute setting. The latter being often referred to as "hot lithotripsy". A criticism of using mobile lithotripters is that efficiency such as overall stone free rates (SFRs), is poorer in comparison to results achieved with a fixed lithotripter. ${ }^{10}$ Current European Association of Urology (EAU) guidelines recommend SWL as a 1st line treatment for both proximal and distal ureteric stones for stones $<10 \mathrm{~mm}$ (2nd line for stones $>10 \mathrm{~mm}$ ). ${ }^{11}$ There is evidence that stones located in the middle third of the ureter can be difficult to localise and therefore treated effectively. However, American Urological Association (AUA) guidelines concluded that SWL does provide stone clearance in the proximal, middle and distal ureter with a stone free rate (SFR) of $82 \%, 73 \%$, and $74 \%$, respectively. ${ }^{12}$ In addition to its less invasive nature, SWL in adults does not require GA and is therefore a treatment option to consider in patients with a high anaesthetic risk profile. Owing to their radiolucency, uric acid calculi require ultrasound (US) or fluoroscopy with contrast to locate the stone accurately and ensure correct shockwave placement.

SWL is less effective for treatment of cystine stones and identification of the stone at time of SWL can be challenging in obese patients, which reinforces how important careful patient selection is. Complications include abdominal pain, haematuria, sepsis, perirenal haematoma and obstruction caused by fragments in the ureter ("steinstrasse"). ${ }^{10}$ Analgesia at the time of SWL is recommended and there is potentially a role for tamsulosin post-procedure to aid in the passage of stone fragments and to help relieve any discomfort or pain. ${ }^{11,12}$ Post-operative imaging is required within the first month (in the form of plain radiography \pm US) and should be expedited if a patient is symptomatic, although CT scan is preferred in some centres.

\section{Recent Advances}

Compared to alternative endourological treatments, there have not been many advancements to the underlying technology since its first description. However, SWL has received attention and has undergone modifications in order to yield better outcomes. Jagtap et al conducted a large series, which identified several factors that may contribute to improved SFR in the context of SWL. ${ }^{13}$ These included better stone localisation, improved coupling, a revision of the current patient and stone selection criteria, reducing shock wave rate and ramping energy, coupled with enhancing lithotripter training. Recent reports have brought attention to prediction models and nomograms and there is emerging evidence highlighting the role of novel urinary biomarkers when identifying or predicting infection or haemorrhage post SWL. ${ }^{14,15}$

\section{Ureteroscopy (URS)}

URS serves both diagnostic and therapeutic purposes. From early cases performed using a paediatric cystoscope, the development of the ureteroscope has come a long way. In 1960, the scope design was revolutionised with the rod lens system, which allowed smaller diameter rigid scopes to be used for URS. The early 1980s saw modelling of the first semi-rigid ureteroscope and its application to remove ureteric calculi for the first time harnessing separate optic and working channels. ${ }^{16}$ Thereafter, with the miniaturisation of scopes, improved durability, and the application of lithotripsy during URS the worldwide popularity of endoscopy has risen and now surpasses that of SWL. ${ }^{8}$ EAU guidelines recommend URS for both proximal and distal ureteric stones. Furthermore, it is recommended as the first line in cases of stones $>10 \mathrm{~mm}$ size. In contrast to its counterparts, there are no reported contraindications to URS. ${ }^{11}$ For example, it can be employed as a safe alternative for obese patients and those with bleeding diatheses. ${ }^{17}$ URS has a low overall complication rate of less than $10 \%$ according to most studies and while it is considered a relatively safe procedure it has been associated with rare, fatal outcomes, mostly linked to sepsis. ${ }^{18,19}$ The most frequently reported complications associated with URS are pain and infection. ${ }^{19}$ In order to reduce complications associated with high intrarenal pressures, recent times have seen a novel type of flexible URS (f-URS) being introduced, which displays both pressure-controlled feedback irrigation systems and suctioning mechanisms. These have been shown to treat even larger upper tract stones safely. ${ }^{20}$ Overall costs of URS 
versus SWL, demonstrate the former is more cost-effective (\$2801) compared to SWL (\$3627) $(p=0.03) .{ }^{21}$

\section{Primary vs Delayed URS}

There is a growing argument supporting the role of primary URS (p-URS) rather than delayed or expectant management of ureteric calculi. The risk of delaying definitive management can exacerbate the existing financial and clinical burden of urolithiasis or complications associated with it. ${ }^{22}$ As rates of URS increase globally, the use of p-URS in the acute setting is also likely to rise. A recent study found no significant differences in terms of operative times, need for postoperative stenting, SFR and complications, between p-URS and delayed URS (d-URS) (which involved initial management with ureteric stenting only). ${ }^{23}$ This suggests that in future the role of $p$-URS and immediate stone removal is likely to be considered over delayed management with stenting. However, there might be a higher failure rate of $p$-URS, and they are generally not recommended in patients with active urinary tract infection. ${ }^{23}$

\section{Scope Design}

Numerous developments in instrumentation have facilitated even safer access to the upper urinary tract through use of both semi-rigid and flexible ureteroscopes. The former is well suited for examination of the distal ureter as they can be easily advanced under vision into the ureteric orifice, allow superior image transmission, provide stability of working instruments and larger working channels. This means higher irrigation pressures can be adopted, which may deliver better views. Semi-rigid URS provides an overall stone clearance rate exceeding $80 \%$ and is particularly successful for treatment of distal ureteric stones. ${ }^{24}$ Over the last few decades, the design of these scopes has changed to become longer, thinner and now even enables access to proximal ureteric stones. ${ }^{25}$

Flexible ureteroscopes (fURS), on the other hand are well designed for upper ureteric and intrarenal stones and as their name suggests, their angles can be manipulated to match to natural course of the ureter. For proximal ureteric stones, they achieve a higher SFR when compared to semi-rigid URS but do not differ significantly in complication rates. ${ }^{26}$ There are fiber-optic or digital flexible ureteroscopes. The former has a smaller diameter, better deflection and is cheaper. Digital scopes hold the advantage of producing higher quality images and do not require additional light cables or camera heads. Since the development of miniaturised, flexible and digital scopes, both access and stone visualisation has vastly improved. Miniaturisation of scopes has expanded the indications to now include stone removal in transplant kidneys. Early fURS models were associated with loss of the maximum active deflection angle upon insertion of accessories such as guidewires. The advent of ureteroscopes with active secondary deflection or continuous deflection to 270 degrees has improved this, which is particularly important where there is an acute infundibulopelvic angle (IPA). ${ }^{26}$ Incorporating a dual working channel in f-URS facilitates continuous irrigation flow in conjunction with insertion of ancillary instruments. This has allowed improved visibility when compared with single-channel ureteroscopes and may give rise to new procedural opportunities. One of latest developments in flexible ureteroscope design are single-use scopes (su-fURS), which hope to combat issues of reprocessing, contamination and costly repairs. ${ }^{27}$ There have been proposals for a "mixed strategy", which integrates the use of both su-fURS and re-fURS. This may prevent re-fURS from unnecessary breakages and allow challenging anatomical cases (eg, steep IPA, which is considered a risk factor for scope damage) to be tackled by sufURS (Table 1). Further cost-effectiveness analyses are needed to ascertain the economic profile of widespread su-fURS use. Furthermore, future studies are warranted, which assess the environmental impact of su-fURS compared to re-fURS. While the former generates more plastic waste, the latter incurs greater energy consumption due to reprocessing. As awareness surrounding climate change is increasing, there will be a greater social responsibility for clinicians to re-evaluate the carbon footprint associated with their practice.

\section{Endourological Armamentarium Guidewires}

Guidewires are an integral tool in endourology. Advantages include improved negotiation of tortuous ureteric segments, overcoming strictures and bypassing impacted stones. The use of safety guidewires during URS has been occasionally debated. ${ }^{28}$ A key advantage they offer is the option to insert a ureteral stent and abort the procedure, should complications arise.

There is a range of guidewires available including hybrid models, which hold differences in shaft stiffness, lubricity and tip configuration. ${ }^{29}$ For instance, flexible hydrophilic-tip wires facilitate access beyond the obstruction with a low risk of perforation, while stiffer shaft wires are designed for difficult ureteral catheterisations, reducing kinking and ureteral access sheath (UAS) or stent insertion. ${ }^{30}$ The use of a 
Table I Overview of Ureteroscopes (*Not Exhaustive List)

\begin{tabular}{|c|c|c|c|c|}
\hline $\begin{array}{l}\text { Type of } \\
\text { Ureteroscope }\end{array}$ & Advantages & Disadvantages & Manufacturer* & Name - Examples* \\
\hline $\begin{array}{l}\text { Re-usable } \\
\text { Semi rigid } \\
\text { ureteroscope }\end{array}$ & $\begin{array}{l}\text { - Allows treatment of all } \\
\text { locations of ureteral } \\
\text { stones } \\
\text {-Relatively less expensive }\end{array}$ & $\begin{array}{l}\text {-Difficult to negotiate } \\
\text { in tortuous and tight } \\
\text { ureter(s) }\end{array}$ & $\begin{array}{l}\text { Olympus } \\
\text { Wolf }\end{array}$ & $\begin{array}{l}\text { OES PRO rage } \\
\text { Needle/Ultra-thin/D. } \\
\text { O.C }\end{array}$ \\
\hline $\begin{array}{l}\text { Single use semi-rigid } \\
\text { ureteroscope }\end{array}$ & Lightweight & $\begin{array}{l}\text {-Limited to one } \\
\text { commercially available } \\
\text { type. } \\
\text {-No studies reporting } \\
\text { its use }\end{array}$ & Neoscope & Neoscope \\
\hline $\begin{array}{l}\text { Reusable flexible } \\
\text { ureteroscope }\end{array}$ & $\begin{array}{l}\text { - Allows treatment of all } \\
\text { locations of stones in the } \\
\text { kidney and mid/proximal } \\
\text { ureter } \\
\text {-In vitro studies reveal } \\
\text { better field of view }\end{array}$ & $\begin{array}{l}\text {-Prone to damage and } \\
\text { costly repairs } \\
\text {-Re-processing is } \\
\text { costly, time consuming } \\
\text { and labour intensive }\end{array}$ & $\begin{array}{l}\text { Olympus } \\
\text { Lumenis } \\
\text { Storz } \\
\text { Wolf }\end{array}$ & $\begin{array}{l}\text { URF-V3/V/P6/P7 } \\
\text { Polyscope } \\
\text { FLEX-Xc/X2(S) } \\
\text { Cobra/Boa/Viper }\end{array}$ \\
\hline $\begin{array}{l}\text { Single use flexible } \\
\text { ureteroscope }\end{array}$ & $\begin{array}{l}\text {-Light weight and digital } \\
\text { technology } \\
\text {-In vitro studies reveal } \\
\text { better deflection and } \\
\text { irrigation properties } \\
\text {-May be better for surgical } \\
\text { training due to less overall } \\
\text { breakage costs. }\end{array}$ & $\begin{array}{l}\text {-Costly to buy upfront } \\
\text {-Worse ecological } \\
\text { impact } \\
\text {-May be worse for } \\
\text { visualising upper tract } \\
\text { tumours }\end{array}$ & $\begin{array}{l}\text { Boston Scientific } \\
\text { Pusen } \\
\text { Maxiflex } \\
\text { Neoscope } \\
\text { Innomedicus } \\
\text { YouCare Technology } \\
\text { Co. } \\
\text { Dornier Med-Tech }\end{array}$ & $\begin{array}{l}\text { LithoVue } \\
\text { Uroscope } \\
\text { SemiFlex } \\
\text { NeoFlex } \\
\text { WIScope } \\
\text { ShaoGang } \\
\text { AXIS }\end{array}$ \\
\hline
\end{tabular}

safety wire is recommended for all ureteroscopy procedures, although it is not mandatory in expert hands. ${ }^{11}$

\section{Working Instruments and Ureteral Access Sheath (UAS)}

The rise in popularity of URS is in part due to improvements in the quantity and quality of working instruments available. These include different styles and sizes of grasping forceps and baskets, which have all been developed to ameliorate safe extraction. UASs, which serve to avoid trauma associated with repeat passage along the course of the upper urinary tract, are a subject of significant discussion. ${ }^{31}$ Reported benefits include improved visibility, reduced operative time, reduced need for high intrarenal pressure and a potential reduction in subsequent complications (infectious or haemorrhagic) as a result (Table 2). However, there are several studies highlighting the limitations of UAS usage. For example, their application may not necessarily correlate with improved SFR. ${ }^{32}$ Prolonged duration of UAS time may be associated with greater post-operative pain. ${ }^{33}$ Selection of optimal size and length of UAS is dependent on the user, and often dictated by the compliance of the ureter. Its use is easier in pre-stented ureters and a shorter length $(35 \mathrm{~cm})$ is generally preferred in females and paediatric patients, while a longer length $(45 \mathrm{~cm})$ is preferred for male patients. $^{11}$

\section{Stents}

Stents are available in various sizes, materials and designs. The main types available are polymeric, metal or biodegradable. ${ }^{34}$ Post-operative stenting is indicated in cases of impacted ureteric calculi, ureteric perforation, solitary kidneys, pregnancy and retroperitoneal fibrosis. Fluoroscopic \pm cystoscopic confirmation of stent position should be performed. There is currently no universal consensus on the recommended duration for post-operative stenting, but standard practice is generally 1 to 2 weeks. Common issues associated with ureteric stents are pain, infection, encrustation and migration. Various treatment options exist for stent-related symptoms including simple and narcotic analgesia, antiinflammatory medications, alpha-blockers and anti- 
Table 2 Overview of New Technologies (*Not Exhaustive List)

\begin{tabular}{|c|c|c|c|c|}
\hline Technology & $\begin{array}{l}\text { Example/ } \\
\text { Manufacturer* }\end{array}$ & Description & Advantages & Disadvantages \\
\hline $\begin{array}{l}\text { Thulium Fiber } \\
\text { laser (TFL) }\end{array}$ & $\begin{array}{l}\text { SOLTIVE (Olympus) } \\
\text { Fiberlase (NTO IRE- } \\
\text { Polus) }\end{array}$ & $\begin{array}{l}\text { Novel laser } \\
\text { technology with } \\
\text { properties which } \\
\text { should allow more } \\
\text { efficient lithotripsy } \\
\text { and reduced } \\
\text { photothermal damage } \\
\text { to other structures. } \\
\text { Uses laser diode } \\
\text { rather than flash lamp. }\end{array}$ & $\begin{array}{l}\text {-Less retropulsion } \\
- \text {-Higher frequency } \\
\text { range (up to } 2400 \mathrm{~Hz} \text { ) } \\
\text {-Faster stone ablation } \\
\text { rate }\end{array}$ & $\begin{array}{l}\text {-Lack of randomised } \\
\text { trials } \\
\text {-No cost data }\end{array}$ \\
\hline $\begin{array}{l}\text { Moses Homium } \\
\text { laser }\end{array}$ & $\begin{array}{l}\text { Moses technology } \\
\text { (Lumenis) } \\
\text { Vapor Tunnel (Quanta } \\
\text { system) }\end{array}$ & $\begin{array}{l}\text { Novel modulation of } \\
\text { laser pulse allows } \\
\text { improved stone } \\
\text { fragmentation as } \\
\text { a result of better } \\
\text { transmission of energy } \\
\text { in water }\end{array}$ & $\begin{array}{l}\text {-Increases ablation } \\
\text { rate } \\
\text {-Reduces retropulsion }\end{array}$ & $\begin{array}{l}\text {-Limited clinical } \\
\text { studies on technology } \\
\text {-Higher cost }\end{array}$ \\
\hline $\begin{array}{l}\text { Anti retropulsive } \\
\text { devices (ARDs) }\end{array}$ & $\begin{array}{l}\text { Stone Cone/Escape/ } \\
\text { Lithocatch/ } \\
\text { Parachute (Boston } \\
\text { Scientific) } \\
\text { NTrap (Cook Medical) } \\
\text { Accordion } \\
\text { (Endotherapeutics) } \\
\text { XenX (Xenolith } \\
\text { Medical) }\end{array}$ & $\begin{array}{l}\text { Prevent retrograde } \\
\text { migration of stone } \\
\text { fragments during } \\
\text { lithotripsy }\end{array}$ & $\begin{array}{l}\text {-Reduced retropulsion } \\
\text { rate } \\
\text {-Potential to reduce } \\
\text { retreatment rate }\end{array}$ & $\begin{array}{l}\text {-Added cost of } \\
\text { procedure (may be } \\
\text { offset by reduced need } \\
\text { additional procedures) } \\
\text {-Some devices liable to } \\
\text { damage from laser } \\
\text {-Some devices not } \\
\text { wide enough for use } \\
\text { dilated ureter(s) }\end{array}$ \\
\hline $\begin{array}{l}\text { Ureteral access } \\
\text { sheath (UAS) }\end{array}$ & $\begin{array}{l}\text { Flexor (Cook Medical) } \\
\text { UroPass (Olympus) } \\
\text { Bi-Flex Evo (Rocamed) } \\
\text { Navigator (Boston } \\
\text { Scientific) }\end{array}$ & $\begin{array}{l}\text { Allow repeat access to } \\
\text { kidney with } \\
\text { ureteroscope }\end{array}$ & $\begin{array}{l}\text {-Decrease intrarenal } \\
\text { pressure } \\
\text {-Repeat and rapid } \\
\text { entry to renal pelvis } \\
\text {-Improved visibility } \\
\text {-Reduced operative } \\
\text { time }\end{array}$ & $\begin{array}{l}\text {-Placement can be } \\
\text { difficult } \\
\text {-Intra-operative } \\
\text { complications eg, tear, } \\
\text { perforation } \\
\text {-Post-operative } \\
\text { complications eg, } \\
\text { stricture } \\
\text {-Over dilation for } \\
\text { insertion }\end{array}$ \\
\hline
\end{tabular}

cholinergics. If symptoms persist, ultimately stent removal may be required. Modern designs include stent on a string which are cost-effective, which can ensure a reduced indwelling time as well as allow the patient to remove the stent safely themselves at home. ${ }^{35}$ Magnetic tipped stents have been designed to mitigate the need for cystoscopic stent removal. $^{36}$ Current evidence appears promising, as they seem to be associated with fewer pain symptoms and have been shown to be cost-effective. Forgotten stents are a serious complication with a rate of up to $12.5 \%{ }^{37}$ Many institutions adopt a "stent register" to combat this complication. More recent developments have included the use of smartphone apps (eg, Urostentz) to monitor this. ${ }^{38}$ Drug-eluting stents are a relatively recent advancement that aims to reduce stentrelated symptoms by delivering medication locally. There are reports showing promising results in terms of lowering pain and voiding symptoms, however further studies are required to validate their use against increased cost. ${ }^{34}$ Patient reported 
outcome measures (PROMS) can be employed in order to assess patient symptoms related to the stent such as Ureteral Stent Symptom Questionnaire (USSQ). ${ }^{39}$ There also exists a PROMs designed to specifically assess symptom burden associated with ureteric stones, the Cambridge Ureteral Stone PROM (CUSP). ${ }^{40}$

Biodegradable stents are currently under investigation and in theory will be able to minimise issues related to stent removal. They may have the potential to also act as a vehicle for local drug delivery. Earlier generations of biodegradable stents were prone to incomplete degradation, and ultimately required removal of fragments making them unsuitable options.

Several in-vivo studies have looked at new materials and methods of biodegradable stent production and have shown promising results. These have included poly-lacticco-glycolic acid (PLGA)/poly-caprolactone, natural polysaccharides, and novel stent shapes with an anti-reflux mechanism that lack the distal coil. ${ }^{41}$ There is also increasing recommendation and use of URS without the use of post-operative stents. It is generally believed that stents are not needed in uncomplicated ureteroscopy, thereby avoiding 'stent symptoms' and complications associated with it. $^{11}$

\section{Lasers}

From the first pulsed dye laser, to the now globally used Holmium: yttrium-aluminium-garnet (Ho:YAG) laser and now with the advent of Thulium fiber laser (TFL), this area remains a hot topic in endourology. Depending on surgeon preference, stone burden and location, varying techniques can be adopted during laser lithotripsy. Recent laser advancements have enabled "dusting" through high frequency and low-power settings, which obviates need for basket retrieval. $^{42}$ Reports show that dusting using thin laser fibres (273 micron) at low power (0.4-0.6 J) and high frequency $(30-50 \mathrm{~Hz})$ reduces the risk of retropulsion. ${ }^{43}$ Pietropaolo et al demonstrated successful outcomes of dusting and pop-dusting methods in patients with large calculi (>15mm). High SFRs were achieved, of $87 \%$ (after first procedure), followed by an increase to $92 \%$ (post-second procedure), which was only required in a minority of cases. ${ }^{44}$ The authors found improved rates of stone breakdown, reduced need for UAS and a low complication rate. While dusting and pop-dusting offer an appealing option in treating large, bilateral or multiple stones in a single setting, fragmentation with basket extraction has been previously deemed superior. ${ }^{45}$
Further studies will be needed to investigate whether dusting leads to greater stone recurrence rates, to clarify the follow-up post-dusting, and to compare outcomes (clinical and financial) with other methods of stone disintegration and removal. Current EAU Guidelines outline Ho-YAG laser as the gold-standard. It is effective in fragmenting stones of any kind and has improved the efficacy of intracorporeal lithotripsy. ${ }^{11}$ A new technique in Ho-YAG laser- the "Moses technology" is currently being investigated for its role in lithotripsy. Recent studies have demonstrated a significant reduction in stone retropulsion when compared with the conventional mode, without compromising ureteral tissue integrity. ${ }^{46}$ This may heighten the efficacy of lithotripsy as the stones move less. The Moses $^{\mathrm{TM}} 200 \mathrm{D} / \mathrm{F} / \mathrm{L}$ fibers are significantly more flexible, which facilitates their use in targeting stones in difficult locations by allowing further fURS deflection.

Thulium fiber laser (TFL) is a newer technology for stone ablation. ${ }^{47}$ It can reach pulse frequencies of up to $2,200 \mathrm{~Hz}$ (in contrast to $100 \mathrm{~Hz}$ with Ho-YAG), a range of very low to very high pulse energies, short to very long pulse durations and a total power of up to $55 \mathrm{~W}$. TFL outperforms Ho: YAG in terms of stone ablation efficiency (it is four-times superior). ${ }^{48}$ Smaller laser fibers can be employed with TFL and this leads to improved irrigation, greater scope deflection, and it indirectly improves access, visualisation and operative time. The apparatus is approximately one-eighth the dimensions of the Ho:YAG laser system and it can be used with standard power outlet.

While still in use in some urological services, pneumatic and ultrasound systems do still serve a role in URS practice, but a common setback includes stone migration, which occurs in 5-40\% of cases. ${ }^{49}$ This problem has been addressed through the development of coupling energy sources of lithotripsy with suction eg, LithoVac ${ }^{\circledR}$. 50 Occlusion devices are techniques with dual function; they prevent stone migration and facilitate capture and removal of fragments. ${ }^{51}$ Their use in forms such as the "Stone Cone" is likely to increase as they mitigate the risk of stone migration, although it is not commonly used. ${ }^{52}$

\section{Medical Expulsive Therapy (MET)}

EAU guidelines acknowledge the potential benefit of MET to facilitate stone passage. ${ }^{11}$ Their effect on ureteric smooth muscle relaxation is thought to improve stone expulsion and aid in symptomatic relief. The advantages of employing MET as a treatment strategy involve a reduced cost burden by avoiding the need for surgery and a subsequent reduction in 
the associated risks of surgery and anaesthesia. Hollingsworth et al performed a meta-analysis of 55 randomised trials, which revealed that taking alpha-blockers significantly reduced pain episodes, time to stone passage and reduced risk of surgical intervention. ${ }^{53}$ However, the role of alpha-blockers in the context of MET still lacks consensus and as a result there is large variation in practice patterns worldwide. ${ }^{54}$

Conservative management of asymptomatic ureteric stones has a spontaneous passage rate of $64 \%{ }^{55}$ This rate for upper, mid and distal ureter was $49 \%, 58 \%$ and $68 \%$, respectively, with $75 \%$ stones $<5 \mathrm{~mm}$ and $62 \%$ stones $\geq 5 \mathrm{~mm}$ passing spontaneously over a mean time of 17 days (range: 6-29 days). Conservative management has also been practiced in asymptomatic live donor kidney stones. ${ }^{56}$ Turgut et al have also evaluated the role of masturbation in spontaneous passage of distal ureteric stone. ${ }^{57}$

\section{Ultrasonic Propulsion}

Ultrasonic propulsion is a novel technique, which can be used pre or post both URS and SWL. ${ }^{58}$ It provides a safe and painless method for transcutaneous repositioning of stones. It has a promising role in facilitating the removal of residual fragments post-procedure and also in repositioning obstructing ureteropelvic junction stones into the kidney for symptomatic control of renal colic. As further clinical trials take place, and the technology is developed, it presents a promising approach to the treatment of ureteric stones in a non-invasive manner. ${ }^{59}$

\section{Artificial Intelligence (AI)}

The last decade has witnessed a paradigm shift harnessing artificial intelligence (AI) in the delivery and decision-making of patient care. AI has been widely used in Urology and has been shown to be accurate for prediction and analysis purposes. ${ }^{60}$ In the context of urolithiasis, the application of AI has allowed localisation of calculi (using computed tomography (CT)/US), detection of stone composition, prediction spontaneous stone passage and outcomes endourological procedures. With the increasing use of electronic databases, the role of $\mathrm{AI}$ is anticipated to expand further.

\section{Endourological Training}

The last two decades have seen a change in attitudes towards surgical skills training. From relying on a predominantly theoretical approach, more practical opportunities are now available with hands-on training through use of both mannequin and virtual reality simulators. ${ }^{61}$ These simulators have a unique role in enhancing a surgeon's visuospatial, stress tolerance and psychomotor skills. Some simulators are now able to record and monitor errors and performance feedback can be given. Use of a standardised training model would optimise endourological treatment of ureteric stone disease. ${ }^{62}$

Several simulation models have been used for training including the Uro-Scopic Trainer (Limbs and Things, Bristol, UK), which is a bench trainer; Scope Trainer (Mediskills Ltd, Edinburgh, UK), also a bench trainer; and URO Mentor (3D Systems, Cleveland, OH, USA), a virtual reality simulator. Flexible ureteroscopy training models include the Key-Box (K-Box ${ }^{\circledR}$, Porgès-Coloplast, France) and the Cook URS Trainer (Cook Medical, Bloomington, IN, USA). ${ }^{63}$

\section{Antegrade Ureteroscopy and Percutaneous Nephrolithotomy (PCNL)}

Most international guidelines advocate use of antegrade URS in cases of large impacted ureteric calculi and for the removal of large stones in transplanted kidneys. ${ }^{11,12}$ In the setting of the latter, retrograde access can be challenging due to the anterior location of the ureteral anastomosis and tortuous ureteric anatomy. The use of a retrograde approach for this non-indexed patient population has a reported $28-60 \%$ incidence of stone retropulsion, which can lead to further secondary procedures and poor SFR. ${ }^{64}$ Antegrade URS avoids these risks and allows for improved visualisation and stone clearance. Disadvantages associated with the antegrade approach include increased operative time and hospital stay, higher radiation exposure and complications linked to the renal puncture. ${ }^{65}$ A recent meta-analysis concluded percutaneous nephrolithotomy (PCNL) to be the most efficient modality in the treatment of large proximal ureteric calculi. ${ }^{66}$ PCNL has been shown to achieve superior SFR when compared with the retrograde approach and is comparable with laparoscopic ureterolithotomy outcomes in terms of stone clearance, procedure time and length of postoperative stay. ${ }^{67}$

While the higher risk of bleeding is a recognised disadvantage associated with standard PCNL (24-30Fr), miniaturisation can mitigate this risk to a certain extent. ${ }^{68,69}$ Sheath sizes are now available as small as 4.85Fr. Mini-PCNL $(<24 \mathrm{Fr})$ has demonstrated improved outcomes in terms of bleeding, postoperative pain and length of hospital stay. Furthermore, its versatility allows for use with various lithotripter probes including ultrasonic, Ho:YAG and now even TFL. ${ }^{48}$ 


\section{Ureteroscopy Under Local Anaesthetic}

The current standard of care involves performing URS under GA. There have been concerns of potential ureteric injuries (eg, sudden patient movement) and patient intolerance when using a local anaesthetic (LA), however existing literature does not confirm this. A recent systematic review supported the practice of URS under LA. ${ }^{70}$ Overall SFR associated with local anaesthesia ranged from 48-100\% while complication rates between LA and GA were comparable. Although mortality from URS is rare, there is a higher-risk patient population, who may be unfit for GA and who would be candidates for LA URS. Currently, SWL is the only alternative option for this cohort but is not necessarily suitable for all patients (eg, those on anticoagulation, larger stones). Although further randomised controlled trials are required to assess and compare outcomes of URS from alternative anaesthetic options, the future of LA URS looks promising and may offer a cost-effective and adaptable option for a certain subgroup of patients.

\section{Ureterolithotomy}

Ureterolithotomy has been occasionally used for large upper ureteral stones. A meta-analysis for URS vs ureterolithotomy showed higher SFR after the initial URS procedure, although the operative and hospital time were in favour of URS. ${ }^{71}$

\section{Conclusion}

While the principles of ureteric stone management have remained largely unchanged, the modern era has generated new methods and means to deliver it. Advancements have occurred in all domains of endourology. Dissemination of technologies and demonstration of their efficacy and safety will eventually result in new recommendations among international guidelines and evolution of new gold standards.

\section{Disclosure}

The authors reported no conflicts of interest for this work.

\section{References}

1. Teichmann HH. Intraureterale lithotripsie [Intraureteral lithrotripsy (author's transl)]. Der Urologe Ausg A. 1980;19(4):231. German.

2. Bagley DH, Huffman JL, Lyon ES. Combined rigid and flexible ureteropyeloscopy. J Urol. 1983;130(2):243-244. doi:10.1016/s00225347(17)51083-6

3. Rukin NJ, Siddiqui ZA, Chedgy ECP, Somani BK. Trends in upper tract stone disease in England: evidence from the hospital episodes statistics database. Urol Int. 2017;98:391-396. doi:10.1159/000449510
4. Antonelli JA, Maalouf NM, Pearle MS, et al. Use of the national health and nutrition examination survey to calculate the impact of obesity and diabetes on cost and prevalence of urolithiasis in 2030. Eur Urol. 2014;66:724-729. doi:10.1016/j.eururo.2014.06.036

5. Geraghty R, Proietti S, Traxer O, Archer M, Somani BK. Worldwide impact of warmer seasons on the incidence of renal colic and kidney stone disease: evidence from a systematic review of literature. J Endourol. 2017;31(8):729-735. doi:10.1089/end.2017.0123

6. Wong Y, Cook P, Roderick P, Somani BK. Metabolic syndrome and kidney stone disease: a systematic review of literature. J Endourol. 2016;30(3):246-253. doi:10.1089/end.2015.0567

7. Ishii $\mathrm{H}$, Couzins $\mathrm{M}$, Aboumarzouk $\mathrm{O}$, et al. Outcomes of systematic review of ureteroscopy for stone disease in obese and morbidly obese population. $J$ Endourol. 2016;30(2):135-145. doi:10.1089/ end.2015.0547

8. Geraghty RM, Jones P, Somani BK. Worldwide trends of urinary stone disease treatment over the last two decades: a systematic review. $J$ Endourol. 2017;31:547-556. doi:10.1089/end.2016. 0895

9. Chaussy C, Brendel W, Schmiedt E. Extracorporeally induced destruction of kidney stones by shock waves. The Lancet. 1980;2:1265-1268. doi:10.1016/S0140-6736(80)92335-1

10. Nafie S, Dyer JE, Minhas JS, et al. Efficacy of a mobile lithotripsy service: a one-year review of 222 patients. Scand J Urol. 2014;48:324-327. doi:10.3109/21681805.2014.886288

11. Türk C, NeIsius A, Petrik A, et al. EAU guidelines on urolithiasis. EAU Guidelines. Edn. presented at the EAU Annual Congress Amsterdam 2020; 2020.

12. Assimos D, Krambeck A, Miller NL, et al. Surgical management of stones: American urological association/endourological society guideline, Part I. J Urol. 2016;196:1153-1160. doi:10.1016/j. juro.2016.05.090

13. Jagtap J, Mishra S, Bhattu A, Ganpule A, Sabnis R, Desai M. 25-year shockwave lithotripsy experience. BJU Int. 2014;114:748-753. doi:10.1111/bju. 12808

14. Yoshioka T, Ikenoue T, Hashimoto H, et al. Development and validation of a prediction model for failed shockwave lithotripsy of upper urinary tract calculi using computed tomography information: the $\mathrm{S}_{3}$ HoCKwave score. World J Urol. 2020;38(12):3267-3273. doi:10.1007/s00345-020-03125-y

15. Brewin A, Sriprasad S, Somani BK. Role of urinary biomarkers for diagnosis and prognosis of kidney stone disease. Curr Opin Urol. 2021;31(2):71-79. doi:10.1097/MOU.0000000000000856

16. Pérez-Castro Ellendt E, Martínez-Piñeiro JA. La ureterorrenoscopia transuretral. Un actual proceder urológico [Transurethral ureteroscopy. A current urological procedure]. Arch Esp Urol. 1980;33 (5):445-460. Spanish.

17. Hiller SC, Qi J, Leavitt D, et al. Ureteroscopy in patients taking anticoagulant or antiplatelet therapy: practice patterns and outcomes in a surgical collaborative. $J$ Urol. 2021;205(3):833-840. doi:10.1097/JU.0000000000001416

18. De Coninck V, Keller EX, Somani B, et al. Complications of ureteroscopy: a complete overview. World J Urol. 2020;38:2147-2166. doi:10.1007/s00345-019-03012-1

19. Whitehurst L, Jones P, Somani BK. Mortality from kidney stone disease (KSD) as reported in the literature over the last two decades: a systematic review. World J Urol. 2019;37(5):759-776. doi:10.1007/ s00345-018-2424-2

20. Huang J, Xie D, Xiong R, et al. The application of suctioning flexible ureteroscopy with intelligent pressure control in treating upper urinary tract calculi on patients with a solitary kidney. Urology. 2018;111:44-47. doi:10.1016/j.urology.2017.07.042

21. Geraghty RM, Jones P, Herrmann TRW, et al. Ureteroscopy is more cost effective than shock wave lithotripsy for stone treatment: systematic review and meta-analysis. World J Urol. 2018;36:1783-1793. doi:10.1007/s00345-018-2320-9 
22. Darrad M, Sibartie T, Inglis J, Rukin N. Is acute ureteroscopy for painful ureteric colic cost effective and beneficial for patients? A cost-analysis. J Clin Urol. 2017;10(1):17-21. doi:10.1177/ 2051415816658417

23. Mckay A, Somani BK, Pietropaolo A, et al. Comparison of primary and delayed ureteroscopy for ureteric stones: a prospective non-randomized comparative study. Urol Int. 2021;105(1-2):90-94. doi:10.1159/000510213

24. Perez Castro E, Osther PJ, Jinga V, et al.; CROES Ureteroscopy Global Study Group. Differences in ureteroscopic stone treatment and outcomes for distal, mid-, proximal, or multiple ureteral locations: the clinical research office of the endourological society ureteroscopy global study. Eur Urol. 2014;66(1):102-109. doi:10.1016/j. eururo.2014.01.011

25. Bagley DH. Ureteroscopic surgery: changing times and perspectives. Urol Clin North Am. 2004;31(1):1-4. doi:10.1016/S0094-0143(03) 00088-0

26. Geavlete P, Multescu R, Geavlete B. Pushing the boundaries of ureteroscopy: current status and future perspectives. Nat Rev Urol. 2014;11(7):373-382.

27. Emiliani E, Traxer O. Single use and disposable flexible ureteroscopes. Curr Opin Urol. 2017;27(2):176-181. doi:10.1097/ MOU.0000000000000371

28. Warde N. Stones: safety guidewire unnecessary during flexible ureteroscopy for routine cases of nephrolithiasis. Nat Rev Urol. 2010;7 (12):645. doi:10.1038/nrurol.2010.193

29. Sarkissian C, Korman E, Hendlin K, Monga M. Systematic evaluation of hybrid guidewires: shaft stiffness, lubricity, and tip configuration. Urology. 2012;79(3):513-517. doi:10.1016/j. urology.2011.10.017

30. Hinck BD, Emmott AS, Omar M, Tarplin S, Chew BH, Monga M. Hybrid guidewires: analysis and comparison of the mechanical properties and safety profiles. Can Urol Assoc J. 2019;13(2):59-63. doi: $10.5489 /$ cuaj.5396

31. Wong VK, Aminoltejari K, Almutairi K, Lange D, Chew BH. Controversies associated with ureteral access sheath placement during ureteroscopy. Investig Clin Urol. 2020;61(5):455-463. doi:10.4111/icu.20200278

32. Abrahams HM, Stoller ML. The argument against the routine use of ureteral access sheaths. Urol Clin North Am. 2004;31(1):83-87. doi:10.1016/S0094-0143(03)00085-5

33. Oğuz U, Şahin T, Şenocak Ç, et al. Factors associated with postoperative pain after retrograde intrarenal surgery for kidney stones. Turk J Urol. 2017;43(3):303-308. doi:10.5152/tud.2017.58997

34. Mosayyebi A, Manes C, Carugo D, Somani BK. Advances in ureteral stent design and materials. Curr Urol Rep. 2018;19(5):35. doi:10.1007/s11934-018-0779-y

35. Oliver R, Wells H, Traxer O, et al.; YAU Group. Ureteric stents on extraction strings: a systematic review of literature. Urolithiasis. 2018;46(2):129-136. doi:10.1007/s00240-016-0898-1

36. Rassweiler MC, Michel MS, Ritter M, Honeck P. Magnetic ureteral stent removal without cystoscopy: a randomized controlled trial. J Endourol. 2017;31(8):762-766. doi:10.1089/end.2017.0051

37. Divakaruni N, Palmer CJ, Tek P, et al. Forgotten ureteral stents: who's at risk? J Endourol. 2013;27(8):1051-1054. doi:10.1089/ end.2012.0754

38. Hameed BMZ, Shah MJ, Naik N, et al. Are technology-driven mobile phone applications (Apps) the new currency for digital stent registries and patient communication: prospective outcomes using urostentz app. Adv Urol. 2021;2021:6612371. doi:10.1155/2021/6612371

39. Joshi HB, Newns N, Stainthorpe A, MacDonagh RP, Keeley FX, Timoney AG. Ureteral stent symptom questionnaire: development and validation of a multidimensional quality of life measure. J Urol. 2003;169(3):1060-1064. doi:10.1097/01. ju.0000049198.53424.1d
40. Tran MGB, Sut MK, Collie J, et al. Development of a disease-specific ureteral calculus patient reported outcome measurement instrument. J Endourol. 2018;32(6):548-558. doi:10.1089/ end.2017.0795

41. Santiago JE, Hollander AB, Soni SD, Link RE, Mayer WA. To dust or not to dust: a systematic review of ureteroscopic laser lithotripsy techniques. Curr Urol Rep. 2017;18(4):32. doi:10.1007/s11934-0170677-8

42. Kang HW, Lee H, Teichman JM, Oh J, Kim J, Welch AJ. Dependence of calculus retropulsion on pulse duration during Ho: YAG laser lithotripsy. Lasers Surg Med. 2006;38(8):762-772. doi:10.1002/1sm.20376

43. Aldoukhi AH, Roberts WW, Hall TL, Ghani KR. Holmium laser lithotripsy in the new stone age: dust or bust? Front Surg. 2017;4:57. doi:10.3389/fsurg.2017.00057

44. Pietropaolo A, Jones P, Whitehurst L, Somani BK. Role of 'dusting and pop-dusting' using a high-powered $(100 \mathrm{~W})$ laser machine in the treatment of large stones $(\geq 15 \mathrm{~mm})$ : prospective outcomes over 16 months. Urolithiasis. 2019;47(4):391-394. doi:10.1007/s00240-0181076-4

45. Humphreys MR, Shah OD, Monga M, et al. Dusting versus basketing during ureteroscopy-which technique is more efficacious? A prospective multicenter trial from the EDGE research consortium. J Urol. 2018;199(5):1272-1276. doi:10.1016/j. juro.2017.11.126

46. Elhilali MM, Badaan S, Ibrahim A, Andonian S. Use of the Moses technology to improve holmium laser lithotripsy outcomes: a preclinical study. J Endourol. 2017;31(6):598-604. doi:10.1089/ end.2017.0050

47. Traxer O, Keller EX. Thulium fiber laser: the new player for kidney stone treatment? A comparison with Holmium: YAG laser. World J Urol. 2020;38(8):1883-1894. doi:10.1007/s00345-019-02654-5

48. Schembri M, Sahu J, Aboumarzouk O, Pietropaolo A, Somani BK. Thulium fiber laser: the new kid on the block. Turk J Urol. 2020;46 (Supp.1):S1-S10. doi:10.5152/tud.2020.20093

49. Binbay M, Tepeler A, Singh A, et al. Evaluation of pneumatic versus holmium: YAG laser lithotripsy for impacted ureteral stones. Int Urol Nephrol. 2011;43(4):989-995. doi:10.1007/s11255-011-9951-8

50. Delvecchio FC, Kuo RL, Preminger GM. Clinical efficacy of combined lithoclast and lithovac stone removal during ureteroscopy. J Urol. 2000;164(1):40-42. doi:10.1016/S0022-5347(05)67444-7

51. Ahmed M, Pedro RN, Kieley S, Akornor JW, Durfee WK, Monga M. Systematic evaluation of ureteral occlusion devices: insertion, deployment, stone migration, and extraction. Urology. 2009;73 (5):976-980. doi:10.1016/j.urology.2008.12.048

52. Fathelbab TK, Abdelhamid AM, Anwar AZM, et al. Prevention of stone retropulsion during ureteroscopy: limitations in resources invites revival of old techniques. Arab J Urol. 2020;18(4):252-256. doi:10.1080/2090598X.2020.1805966

53. Hollingsworth JM, Canales BK, Rogers MA, et al. Alpha blockers for treatment of ureteric stones: systematic review and meta-analysis. BMJ. 2016;355:i6112. doi:10.1136/bmj.i6112

54. Veser J, Seitz C. The status of medical expulsive therapy in the age of evidence-based medicine. Ann Transl Med. 2018;6(Suppl 1):S18. doi:10.21037/atm.2018.09.09

55. Yallapa S, Amer T, Jones P, et al. Natural history of conservatively managed ureteral stones: analysis of 6600 patients. J Endourol. 2018;32(5):371-379. doi:10.1089/end.2017.0848

56. Turgut H, Sarier M. Evaluation of the efficacy of masturbation on distal ureteral stones: a prospective, randomized, controlled study. Int Urol Nephrol. 2020. doi:10.1007/s11255-020-02672-y

57. Sarier M, Duman I, Callioglu M, et al. Outcomes of conservative management of asymptomatic live donor kidney stones. Urology. 2018;118:43-46. doi:10.1016/j.urology.2018.04.035 
58. May PC, Bailey MR, Harper JD. Ultrasonic propulsion of kidney stones. Curr Opin Urol. 2016;26(3):264-270. doi:10.1097/ MOU.0000000000000276

59. Harper JD, Cunitz BW, Dunmire B, et al. First in human clinical trial of ultrasonic propulsion of kidney stones. J Urol. 2016;195(4 Part 1):956-964. doi:10.1016/j.juro.2015.10.131

60. Shah M, Naik N, Somani BK, Hameed BMZ. Artificial intelligence (AI) in urology-current use and future directions: an iTRUE study. Turk J Urol. 2020;46(Supp. 1):S27-S39. doi:10.5152/tud.2020.20117

61. Kozan AA, Chan LH, Biyani CS. Current status of simulation training in urology: a non-systematic review. Res Rep Urol. 2020;12:111-128. doi:10.2147/RRU.S237808

62. Veneziano D, Ploumidis A, Proietti S, et al.; ESU Training Group. Validation of the endoscopic stone treatment step 1 (EST-s1): a novel EAU training and assessment tool for basic endoscopic stone treatment skills-a collaborative work by ESU, ESUT and EULIS. World J Urol. 2020;38(1):193-205. doi:10.1007/s00345-019-02736-4

63. Veneziano D, Ahmed K, Van Cleynenbreugel B, et al. Development methodology of the novel endoscopic stone treatment step 1 training/ assessment curriculum: an international collaborative work by European Association of Urology sections. J Endourol. 2017;31 (9):934-941. doi:10.1089/end.2017.0248

64. Elgebaly O, Abdeldayem H, Idris F, Elrifai A, Fahmy A. Antegrade mini-percutaneous flexible ureteroscopy versus retrograde ureteroscopy for treating impacted proximal ureteric stones of 1-2 cm: a prospective randomised study. Arab J Urol. 2020;18(3):176-180. doi:10.1080/2090598X.2020.1769385

65. Winter M, Lynch C, Appu S, Kourambas J. Surgery illustrated-focus on details: access sheath-aided percutaneous antegrade ureteroscopy; a novel approach to the ureter. BJU Int. 2011;108(4):620-622. doi:10.1111/j.1464-410X.2011.10538.x
66. Lai S, Jiao B, Diao T, et al. Optimal management of large proximal ureteral stones $(>10 \mathrm{~mm})$ : a systematic review and meta-analysis of 12 randomized controlled trials. Int J Surg. 2020;80:205-217. doi:10.1016/j.ijsu.2020.06.025

67. Xiao-jian G, Lin LJ, Yan X. Treatment of large impacted proximal ureteral stones: randomized comparison of minimally invasive percutaneous antegrade ureterolithotripsy versus retrograde ureterolithotripsy. World J Urol. 2013;31(6):1605-1610. doi:10.1007/s00345-013-1026-2

68. Proietti S, Giusti G, Desai M, Ganpule AP. A critical review of miniaturised percutaneous nephrolithotomy: is smaller better? Eur Urol Focus. 2017;3(1):56-61. doi:10.1016/j.euf.2017.05.001

69. Wright A, Rukin N, Smith D, et al. 'Mini, ultra, micro' - nomenclature and cost of these new minimally invasive percutaneous nephrolithotomy (PCNL) techniques. Ther Adv Urol. 2016;8(2):142-146. doi: $10.1177 / 1756287215617674$

70. Schembri M, Agarwal V, Pietropaolo A, Somani B. Outcomes of loco-regional anaesthesia in ureteroscopy for stone disease: a systematic review. Curr Opin Urol. 2020;30(5):726-734. doi:10.1097/MOU.0000000000000791

71. Kallidonis P, Ntasiotis P, Knoll T, et al. Minimally invasive surgical ureterolithotomy versus ureteroscopic lithotripsy for large ureteric stones: a systematic review and meta-analysis of the literature. Eur Urol Focus. 2017;3(6):554-566. doi:10.1016/j.euf.2017.04.006

\section{Publish your work in this journal}

Research and Reports in Urology is an international, peer-reviewed, open access journal publishing original research, reports, editorials, reviews and commentaries on all aspects of adult and pediatric urology in the clinic and laboratory including the following topics: Pathology, pathophysiology of urological disease; Investigation and treatment of urological disease; Pharmacology of drugs used for the treatment of urological disease. The manuscript management system is completely online and includes a very quick and fair peer-review system, which is all easy to use. Visit http://www.dovepress.com/ testimonials.php to read real quotes from published authors 